\title{
PENGARUH FAKTOR SOSIAL EKONOMI PETANI DAN PARTISIPASI PETANI DALAM PENERAPAN TEKNOLOGI POLA TANAM PADI (Oryza sativa L) JAJAR LEGOWO 4 : 1
}

(Studi Kasus pada Kelompoktani Gunung Harja di Desa Kalijaya

Kecamatan Banjarsari Kabupaten Ciamis)

\author{
Oleh : \\ Sri Mulyati ${ }^{1}$, Dini Rochdiani ${ }^{2}$, Muhamad Nurdin Yusuf ${ }^{3}$ \\ ${ }^{13}$ Fakultas Pertanian Universitas Galuh \\ ${ }^{2}$ Fakultas Pertanian Universitas Padjadjaran
}

\begin{abstract}
Abstrak
Penelitian ini bertujuan untuk mengetahui 1) Tingkat partisipasi petani dalam penerapan teknologi pola tanam padi jajar legowo $4: 1$. 2) Karakteristik sosial ekonomi petani yang menerapkan teknologi pola tanam padi jajar legowo $4: 1$. 3) Faktor-faktor yang berpengaruh terhadap penerapan teknologi pola tanam padi jajar legowo 4 : 1. Jenis penelitian yang digunakan dalam penelitian ini adalah metode studi kasus (case study) di Kelompoktani Gunung Harja Desa Kalijaya Kecamatan Banjarsari Kabupaten Ciamis. Sampel yang diambil adalah semua anggota Kelompoktani Gunung Harja sebanyak 24 orang.

Hasil penelitiannya adalah : 1)Tingkat partisipasi petani dalam Kelompoktani Gunung Harja termasuk dalam kategori tinggi dengan jumlah 13 orang atau 54,16 persen, dan yang berada pada kategori rendah sebanyak 11 orang atau 45,83 persen. 2) Karakteristik sosial ekonomi petani berada pada kategori sedang yaitu sebanyak 11 orang atau 45,83 persen, kategori tinggi sebanyak 7 orang atau 29,17 persen, dan yang terakhir berada pada kategori rendah sebanyak 6 orang atau 25 persen. 3)Faktor sosial ekonomi petani yang meliputi, umur responden, tingkat pendidikan formal dan non formal, jumlah tanggungan keluarga, luas lahan, frekuensi mengikuti penyuluhan dan pengalaman bertani secara simultan dan parsial berpengaruh signifikan terhadap penerapan teknologi pola tanam padi jajar legowo $4: 1$.
\end{abstract}

\section{Kata Kunci : Kelompoktani, Jajar Legowo 4 :1.}

\section{PENDAHULUAN}

Indonesia sebagai negara berkembang memiliki produktivitas pertanian yang sangat rendah. Hal ini berdampak nyata terhadap situasi perekonomian nasional yaitu impor beras meningkat, inflasi menjadi tak terkendali, kekurangan pangan dan kesempatan kerja terbatas sehingga menimbulkan pengangguran. Pembangunan pertanian merupakan langkah awal dalam strategi pembangunan nasional jangka panjang (Firdaus, 2008). Pembangunana pertanian menghendaki pertanian yang dinamis yaitu pertanian yang bercirikan antara lain dengan penggunaan teknologi baru yang berlangsung secara terus-menerus, berkesinambungan dan peran serta petani dan keluarganya dalam melaksanakan kegiatan usahataninya (Ginting, 2011). Pembangunan sektor pertanian selalu dikaitkan dengan kondisi kehidupan para petani, daerah perdesaan tempat dimana mayoritas petani menjalani kehidupannya mempunyai beberapa permasalahan seperti tingkat pendidikan rendah, adanya sikap mental yang kurang mendukung dan masalah-masalah lainnya. Permasalahan tersebut meliputi seluruh aspek kehidupan masyarakat petani perdesaan yang satu sama lain saling berkaitan (Negara, 2000 dalam
Sholeh, 2013). Partisipasi petani dalam mengikuti kegiatan di kelompoktani dipengaruhi oleh banyak faktor. Beberapa faktor yang berhubungan dengan tingkat partisipasi diantaranya adalah faktor-faktor yang berasal dari masyarakat itu sendiri, misal dari karakteristik sosial ekonomi petani sendiri (Hasyim, 2006).

Hasil penelitian Misran (2014) menunjukkan bahwa sistem tanam jajar legowo dapat meningkatkan hasil gabah kering panen sekitar 19,90 - 22\%. Hasil penelitiannya merekomendasikan bahwa untuk mendapatkan hasil yang optimal disarankan menggunakan sistem tanam secara jajar legowo.

Berdasarkan kajian pada latar belakang, maka permasalahan yang dapat diidentifikasikan adalah sebagai berikut :

1. Bagaimana tingkat partisipasi petani dalam penerapan teknologi pola tanam padi jajar legowo $4: 1$ ?

2. Bagaimana karakteristik sosial ekonomi petani yang menerapkan teknologi pola tanam padi jajar legowo $4: 1$ ? 
3. Faktor-faktor apa saja yang berpengaruh terhadap penerapan teknologi pola tanam padi jajar legowo $4: 1$ ?

\section{METODE PENELITIAN Jenis Penelitian}

Metode penelitian yang digunakan dalam penelitian ini adalah metode studi kasus, dengan mengambil kasus pada Kelompoktani "Gunung Harja"di Dusun Karang Sari Desa Kalijaya Kecamatan Banjarsari Kabupaten Ciamis.

\section{Operasionalisasi Variabel}

1. Karakteristik sosial ekonomi petani yang meliputi

a. Umur (X1) adalah usia petani yang dihitung dari tanggal lahirnya sampai pada penyebaran kuisioner. Yang dibedakan menurut kategori (1) antara 22-40 tahun, (2) antara $42-56$ tahun, dan (3) antara 57 - 65 tahun.

b. -Tingkat Pendidikan Formal (X1) adalah lama pendidikan formal yang ditempuh petani di bangku sekolah yang dibedakan menurut kategori (1) $\leq$ SD,SMP/MTs, (2) SMA/SMK, (3) Perguruan tinggi,DI,DII,DIII.

- Tingkat Pendidikan Non Formal adalah pendidikan yang pernah diikuti oleh petani baik itu pelatihan pertanian, pertemuan kelompok ataupun penyuluhan tentang pertanian.yang dibedakan dalam kategori (1) tidak pernah, (2) 1 - 3 kali, dan (3) $\geq 3$ kali.

c. Jumlah Tanggungan Keluarga (X4) adalah banyaknya orang dalam keluarga yang menjadi tanggungan responden (jiwa), dibedakan dalam kategori dibedakan dalam kategori (1) sedikit 1-2 jiwa, (2) sedang 3-4 jiwa dan (3) banyak $\geq 4$ jiwa.

d. Luas Lahan adalah keseluruhan lahan yang dimiliki petani dalam usaha pertanian, dibedakan dalam kategori (1) sempit $\leq 0,25$ ha, (2) sedang 0,25 - 0,50 ha, dan (3) luas $\geq$ 0,50 ha.

e. Frekuensi Mengikuti Penyuluhan banyaknya atau rutinitas partisipasi dalam mengikuti penyuluhan selama satu musim tanam, yang dibedakan dalam kategori (1) rendah 1-2 kali, (2) sedang 3-5 kali, dan (3) tinggi 6-8 kali.

f. Pengalaman Bertani adalah lama petani melakukan usaha tani padi sawah dihitung mulai usahataninya hingga saat penelitian dilaksanakan (tahun) dibedakan dalam kategori (1) pemula $\leq 10$ tahun, (2) berpengalaman 11-20 tahun, dan (3) sangat berpengalaman $\geq 20$ tahun.
2. Kelompoktani adalah sejumlah petani yang tergabung dalam satu hamparan/wilayah yang dibentuk atas dasar kesamaan kepentingan untuk meningkatkan usaha agribisnis dan memudahkan pengelolaan dalam proses distribusi, baik itu benih, pestisida, sarana produksi dan lain-lain.

3. Tingkat Partisipasi Petani adalah bentuk keterlibatan dan keikutsertaan masyarakat secara aktif dan sukarela, baik karena alasan-alasan dari dalam dirinya maupun dari luar dirinya dalam keseluruhan proses kegiatan yang meliputi : frekuensi kehadiran dalam petemuan, keaktifan kelompok dalam berdiskusi, keterlibatan dalam kegiatan fisik dan kesediaan membayar iuran atau sumbangan.

\section{Teknik Pengumpulan Data}

Jenis data yang digunakan dalam penelitian ini adalah data primer dan data sekunder.

1).Data primer diperoleh melalui wawancara langsung secara mendalam dan juga penyebaran kuesioner kepada responden, di samping itu data primer juga diperoleh peneliti selama di lapangan melalui observasi. Sebelum kuisioner disebarkan, kuisioner tersebut diuji validitas dan realibilitasnya terlebih dahulu. Validitas adalah tingkat keandalan dan kesahihan alat ukur yang digunakan. Uji validitas berguna untuk mengetahui apakah ada pertanyaan/pernyataan pada kuisioner yang harus dibuang atau diganti karena dianggap tidak relevan.Uji reliabilitas berguna untuk menetapkan apakah instrumen yang digunakan dapat digunakan lebih dari satu kali, paling tidak oleh responden yang sama akan menghasilkan data yang konsisten.

2).Data sekunder diperoleh dengan cara mengumpulkan data dari pihak-pihak lain diantaranya adalah instansi terkait (BP3K KP Kecamatan Banjarsari, BP4K KP Kabupaten Ciamis, Kantor Desa Kalijaya), studi kepustakaan dan sumber lain yang turut menunjang dalam penelitian ini.

\section{Rancangan Analisis Data \& Uji Hipotesis \\ Rancangan Analisis Data}

1). Tingkat Penerapan Teknologi Jajar Legowo $4: 1$ dibagi menjadi tiga kategori yaitu Rendah, Sedang, dan Tinggi. Penghitungan menggunakan rumus menurut Sudjana (2002) sebagai berikut :

$$
\begin{aligned}
\mathrm{R} & =\frac{\text { Nilai Maksimal-Nilai Minimal }}{\text { Jumlah Kategori }} \\
& =\frac{18-6}{3}=4
\end{aligned}
$$


Dari perhitungan tersebut maka dapat diketahui kategori karakteristik petani pengguna pola tanam jajar legowo 4 : 1 yaitu :

1. Tingkat Karakteristik Petani Rendah

$$
(6 \leq \mathrm{Q}<10)
$$

2. Tingkat Karakteristik Petani Sedang

$$
(10 \leq \mathrm{Q}<14)
$$

3. Tingkat Karakteristik Petani Tinggi

$$
(14 \leq \mathrm{Q} \leq 18)
$$

Keterangan : Q adalah Nilai yang dicapai.

Indikator tingkat partisipasi petani dan kisaran skor dalam kelompoktani di kategorikan menjadi Rendah, Sedang, Tinggi dengan menggunakan rumus menurut Sudjana (2002) sebagai berikut

$$
\begin{aligned}
\mathrm{R} & =\frac{\text { Nilai Maksimal-Nilai Minimal }}{\text { Jumlah Kategori }} \\
& =\frac{32-4}{3}=9,33
\end{aligned}
$$

Sehingga diperoleh pengukuran indikatorindikator variabel faktor partisipasi sebagai berikut :

a) Rendah : $4 \leq \mathrm{Q}<13,33$

b) Sedang : $13.34 \leq \mathrm{Q}<22,66$

c) Tinggi : 22,67 $\leq \mathrm{Q}<32$

Keterangan : Q adalah nilai yang dicapai.

2). Untuk melihat pengaruh faktor sosial ekonomi petani terhadap tingkat penerapan teknologi jajar legowo 4 : 1 menggunakan model persamaan sebagai berikut :

$Y=b_{0}+b_{1} X_{1}+b_{2} X_{2}+b_{3} X_{3}+b_{4} X_{4}+b_{5} X_{5}+b_{6} X_{6}+e$ Keterangan :

$\mathrm{Y}=$ Tingkat penerapan teknologi pola tanam padi jajar legowo $4: 1$

$\mathrm{b}_{0}=$ Intersep/ konstanta

$\mathrm{X}_{1}=$ Umur Peani

$\mathrm{X}_{2}=$ Pendidikan formal \& Non formal yang ditempuh petani

$\mathrm{X}_{3}=$ Jumlah Tanggungan Keluarga

$\mathrm{X}_{4}=$ Luas Lahan

$\mathrm{X}_{5}=$ Frekuensi Mengikuti Penyuluhan

$\mathrm{X}_{6}=$ Pengalaman Bertani

$b_{i}=$ Koefisien arah garis regresi

e $=$ Faktor lain

Uji Asumsi Klasik

Uji asumsi klasik digunakan untuk mengetahui apakah hasil analisis regresi linier berganda yang digunakan dalam penelitian ini terbebas dari penyimpangan asumsi klasik yang meliputi uji normalitas, multikolinieritas, heteroskedastisitas dan autokorelasi. Adapun masing-masing pengujian tersebut meliputi uji normalitas, uji multikolinieritas, uji heteroskedostisitas, dan uji autokorelasi.

\section{HASIL DAN PEMBAHASAN \\ Uji Asumsi Klasik}

Berdasarkan hasil uji asumsi klasik menggunakan SPSS 23.0, menunjukkan bahwa pada uji normalitas data variabel terikat dan bebas mempunyai data yang terdistribusi normal. Pada uji multikolinieritas menunjukkan tidak terjadi korelasi, pada grafik uji heteroskedositas tidak ada pola yang jelas maka mengindikasikan tidak terjadi gejala heteroskedositas, dan pada uji autokorelasi angka D$\mathrm{W}$ di atas +2 hal ini menunjukkan tidak ada autokorelasi yang negatif.

\section{Partisipasi Petani Dalam Penerapan Teknologi Pola Tanam Padi Jajar Legowo 4 : 1}

Dalam sub ini dibahas tentang partisipasi kelompok dalam pelaksanaan kegiatan di Kelompoktani Gunung Harja. Derajat keterlibatan petani/masyarakat diukur dari variabel-variabel tingkat kehadiran dalam pertemuan, keaktifan dalam berdiskusi, keterlibatan dalam kegiatan fisik dan kesepakatan untuk membayar iuran atau sumbangan.

Konsep partisipasi yang digunakan dalam penelitian ini adalah konsep partisipasi Sherry Arstein (1969) yang lebih dikenal dengan "Delapan Tangga Partisipasi Arstein". Konsep ini membagi tingkat partisipasi ke dalam delapan tingkatan partisipasi yang digolongkan kedalam tiga golongan besar. Pertama adalah derajat terbawah, yaitu non participation (manipulation dan therapy), derajat menengah atau derajat semu yaitu dgress of tokenism (information, consultation, dan placation), dan terakhir adalah derajat tertinggi yaitu dgress of citizen power (partnership, delegated power dan citizen control). Dari keempat analisis tersebut, sehingga diperoleh tingkat partisipasi kelompok dalam kegiatan di Kelompoktani Gunung Harja sebagaimana pada Tabel 1 berikut ini.

\section{Tabel 1. Tingkat Partisipasi Dalam Kelompoktani}

\begin{tabular}{|c|c|c|c|}
\hline \multirow{2}{*}{ No } & Kategori & \multicolumn{2}{|c|}{ Jumlah } \\
\cline { 3 - 4 } & & $\begin{array}{c}\text { Responden } \\
\text { (Orang) }\end{array}$ & $\begin{array}{c}\text { Persentase } \\
(\%)\end{array}$ \\
\hline 1. & Sedang & 11 & 45,83 \\
\hline 2. & Tinggi & 13 & 54,17 \\
\hline \multicolumn{2}{|c|}{ Jumlah } & $\mathbf{2 4}$ & $\mathbf{1 0 0 , 0 0}$ \\
\hline
\end{tabular}

Berdasarkan Tabel 1 menunjukkan bahwa tingkat partisipasi petani dalam Kelompoktani mempunyai kategori tinggi dengan jumlah responden 13 orang atau 54,17 persen hal ini menunjukkan bahwa tingkat partisipasi petani berada pada derajat tertinggi yaitu 
dgress of citizen power (partnership, delegated power dan citizen control), sedangkan yang berada pada kategori rendah sebanyak 11 orang atau 45,83 persen.

\section{Identitas Responden}

Identitas Petani dalam hal ini adalah anggota Kelompoktani Gunung Harja yang menjadi responden yang dibahas dalam penelitian ini meliputi luas pemilikan lahan, umur, pendidikan, jumlah tanggungan dalam keluarga, pengalaman bertani dan frekuensi mengikuti penyuluhan menjadi anggota kelompoktani.

\section{Umur Responden}

Umur merupakan salah satu faktor yang dapat mempengaruhi kemampuan seseorang dalam bekerja, semakin tua umur seseorang maka kemampuan fisik dalam bekerja semakin berkurang. Data selengkapnya mengenai umur responden dapat dilihat pada Tabel 2 berikut ini.

Tabel 2. Karakteristik Sosial Ekonomi Petani Berdasarkan Umur Responden

\begin{tabular}{|c|c|c|c|}
\hline \multirow{2}{*}{ No } & Umur & \multicolumn{2}{|c|}{ Jumlah } \\
\cline { 3 - 4 } & & $\begin{array}{c}\text { Responden } \\
(\text { Orang) }\end{array}$ & $\begin{array}{c}\text { Persentase } \\
(\%)\end{array}$ \\
\hline 1. & $22-40$ & 7 & 29,17 \\
\hline 2. & $42-56$ & 9 & 37,5 \\
\hline 3. & $57-65$ & 8 & 33,33 \\
\hline \multicolumn{2}{|c|}{ Jumlah } & $\mathbf{2 4}$ & $\mathbf{1 0 0 , 0 0}$ \\
\hline
\end{tabular}

Berdasarkan Tabel 2 sebagian besar umur responden berkisar antara $42-56$ sebanyak 9 orang atau 37,5 persen, 57 - 65 sebanyak 8 orang atau 33,33 persen, dan yang paling sedikit $22-40$ sebanyak 7 orang atau 29,17 orang. Keseluruhan responden berada pada usia produktif. Hal ini sesuai dengan pendapat Mantra (2000) yang menyatakan bahwa penduduk usia produktif adalah penduduk yang berumur $15-64$ tahun.

\section{Pendidikan Responden}

Tingkat pendidikan formal yang ditempuh oleh petani responden di Kelompoktani Gunung Harja Desa Kalijaya Kecamatan Banjarsari Kabupaten Ciamis pada penerapan teknologi pola tanam padi jajar legowo $4: 1$ dapat dilihat pada Tabel 3 berikut ini.
Tabel 3.Karakteristik Sosial Ekonomi Berdasarkan Tingkat Pendidikan Formal Responden

\begin{tabular}{|c|l|c|c|}
\hline \multirow{2}{*}{ No. } & \multirow{2}{*}{ Pendidikan } & \multicolumn{2}{|c|}{ Jumlah } \\
\cline { 3 - 4 } & & Orang & \% \\
\hline 1. & Tamat SD / SMP & 24 & 100 \\
\hline 2. & Tamat SMA & 0 & 0 \\
\hline 3. & Perguruan Tinggi & 0 & 0 \\
\hline \multicolumn{2}{|c|}{ Jumlah } & $\mathbf{2 4}$ & $\mathbf{1 0 0 , 0 0}$ \\
\hline
\end{tabular}

Tabel 3 menunjukkan bahwa pendidikan responden tergolong masih rendah, dimana semua responden yaitu sebanyak 24 orang atau 100 persen memiliki pendidikan setara SD / SMP. Rendahnya tingkat pendidikan ini akan menjadi kendala dalam mengadopsi teknologi yang diperlukan dalam menjalankan usahataninya.

\section{Tabel 4.Karakteristik Sosial Ekonomi Berdasarkan Tingkat Pendidikan Non Formal Responden}

\begin{tabular}{|c|c|c|c|}
\hline \multirow{2}{*}{ No. } & \multirow{2}{*}{ Pendidikan } & \multicolumn{2}{|c|}{ Jumlah } \\
\cline { 3 - 4 } & & Orang & $\mathbf{\%}$ \\
\hline 1. & $1-3$ kali & 14 & 58,33 \\
\hline 2. & $\geq 3$ kali & 10 & 41,67 \\
\hline \multicolumn{2}{|c|}{ Jumlah } & $\mathbf{2 4}$ & $\mathbf{1 0 0 , 0 0}$ \\
\hline
\end{tabular}

Tabel 4 menunjukkan bahwa pendidikan non formal responden tergolong sedang, dimana responden yang pernah mengikuti pendidikan non formal antara $1-3$ kali sebanyak 14 orang atau 58,33 persen dan yang kedua adalah yg lebih dari tiga kali sebanyak 10 orang atau 41,67 persen. Pendidikan menunjukkan tingkat pengetahuan dan perilaku sesorang serta mempengaruhi cara berfikir petani dalam menerima sesuatu yang baru (inovasi). Untuk itu perlu dipertimbangkan peningkatan pendidikan melalui pendidikan non formal, misalnya melalui kegiatan penyuluhan pertanian ataupun workshop pertanian.

\section{Jumlah Tanggungan Keluarga}

Jumlah tanggungan keluarga disini adalah anggota keluarga yang ditanggung oleh kepala keluarga dan istri meliputi, anak, atau seseorang yang dianggap keluarga. Jumlah anak dalam keluarga dari 
responden penelitian berkisar antara $1-5$ orang. Data selengkapnya mengenai jumlah anak dalam keluarga dapat dililhat pada Tabel 5 berikut ini.

Tabel 5.Karakteristik Sosial Ekonomi Berdasarkan Jumlah Tanggungan Dalam Keluarga

\begin{tabular}{|c|c|c|c|}
\hline \multirow{2}{*}{ No } & $\begin{array}{c}\text { Jumlah Tanggungan } \\
\text { Dalam Keluarga } \\
\text { (orang) }\end{array}$ & \multicolumn{2}{|c|}{ Jumlah } \\
\cline { 3 - 4 } & $1-2$ & 18 & $\%$ \\
\hline 1 & $3-4$ & 6 & 25 \\
\hline 2 & Jumlah & $\mathbf{2 4}$ & $\mathbf{1 0 0 , 0 0}$ \\
\hline
\end{tabular}

Berdasarkan Tabel 5 menunjukkan bahwa sebagian besar responden mempunyai jumlah tanggungan dalam keluarga antara 1 - 2 orang yaitu sebanyak 18 orang atau 75 persen, dan yang memiliki tanggungan antara $3-4$ orang sebanyak 6 orang atau 25 persen.

\section{Luas Pemilikan Lahan}

Luas lahan yang diusahakan untuk budidaya tanaman pertanian berkaitan dengan skala usaha, dimana semakin luas lahan yang diusahakan maka semakin besar skala usahanya. Data selengkapnya mengenai luas lahan dapat dilihat pada Tabel 6.

\section{Tabel 6.Karakteristik Sosial Ekonomi Berdasarkan Luas Lahan Responden}

\begin{tabular}{|c|c|c|c|}
\hline \multirow{2}{*}{ No. } & \multirow{2}{*}{$\begin{array}{c}\text { Luas Lahan } \\
\text { (Hektar) }\end{array}$} & \multicolumn{2}{|c|}{ Jumlah } \\
\cline { 3 - 4 } & $<0,25$ & Orang & \% \\
\hline 1. & & 3 & 12,5 \\
\hline 2. & $0,25-0,50$ & 12 & 50 \\
\hline 3. & $>0,50$ & 9 & 37,5 \\
\hline \multicolumn{2}{|c|}{ Jumlah } & $\mathbf{2 4}$ & $\mathbf{1 0 0 , 0 0}$ \\
\hline
\end{tabular}

Berdasarkan Tabel 6 menunjukkan bahwa sebagian besar responden memiliki lahan antara 0,25 - 0,50 hektar, yaitu sebanyak 12 Orang atau 50 persen dari jumlah responden keseluruhan. Dengan demikian sebagian besar responden termasuk kedalam golongan petani dengan pemilikan lahan yang luas. Hal ini sesuai dengan pendapat Suratiyah (2006) yang menyatakan bahwa penguasaan lahan kurang dari 0,25 hektar termasuk kategori sempit, antara 0,25 hektar sampai 0,50 hektar termasuk kategori sedang, apabila lebih dari 1 hektar termasuk kategori luas.

\section{Frekuensi Mengikuti Penyuluhan}

Frekuensi mengikuti penyuluhan atau rutinitas responden dalam mengikuti kegiatan penyuluhan selama satu musim tanam, untuk lebih jelasnya dapat dilihat pada Tabel 7 berikut ini.

\section{Tabel 7.Karakteristik Sosial Ekonomi Berdasarkan Frekuensi Mengikuti Penyuluhan}

\begin{tabular}{|c|c|c|c|}
\hline \multirow[t]{2}{*}{ No. } & \multirow{2}{*}{$\begin{array}{c}\text { Frekuensi Mengikuti } \\
\text { Penyuluhan }\end{array}$} & \multicolumn{2}{|c|}{ Jumlah } \\
\hline & & $\begin{array}{c}\text { Responden } \\
\text { (Orang) }\end{array}$ & $\begin{array}{c}\text { Persentase } \\
(\%)\end{array}$ \\
\hline 1. & $1-2$ & 2 & 8,33 \\
\hline 2. & $3-5$ & 9 & 37,5 \\
\hline 3. & $6-8$ & 13 & 54,17 \\
\hline & Jumlah & 24 & 100,00 \\
\hline
\end{tabular}

Berdasarkan data dari Tabel 7 diatas diketahui bahwa sebagian besar responden pernah mengikuti penyuluhan antara $6-8$ kali sebanyak 13 orang atau 54,17 persen kemudian yang pernah mengikuti penyuluhan antara $3-5$ kali sebanyak 9 orang atau 37,5 persen.

\section{Pengalaman Bertani}

Pengalaman bertani sangat penting dalam menentukan keberhasilan usahatani padi sawah, karena dengan pengalaman pada usahatani padi sawah mereka akan lebih terampil dalam mengatasi hambatan maupun tantangan yang mungkin terjadi pada usahatani berlangsung. Adapun pengalaman sampel disajikan pada Tabel 8 berikut ini. 
Tabel 8. Karakteristik Sosial Ekonomi Berdasarkan Pengalaman Bertani

\begin{tabular}{|c|c|c|c|}
\hline \multirow[t]{2}{*}{ No } & \multirow{2}{*}{$\begin{array}{c}\text { Pengalaman } \\
\text { Bertani }\end{array}$} & \multicolumn{2}{|c|}{ Jumlah } \\
\hline & & $\begin{array}{c}\text { Responden } \\
\text { (Orang) }\end{array}$ & $\begin{array}{c}\text { Persentase } \\
(\%)\end{array}$ \\
\hline 1 & $\leq 10$ tahun & 7 & 29,17 \\
\hline 2 & $11-20$ & 9 & 37,5 \\
\hline 3 & $\geq 20$ tahun & 8 & 33,33 \\
\hline & Jumlah & 24 & 100,00 \\
\hline
\end{tabular}

Berdasarkan Tabel 8 dapat diketahui bahwa pengalaman bertani responden sebagian besar 11 20 tahun sebanyak 9 orang atau 37,5 persen, kedua terbesar diatas 20 tahun sebanyak 8 orang atau 33,33 persen, dan yang paling sedikit yang mempunyai pengalaman bertani kurang dari 10 tahun sebanyak 7 orang atau 29,17 persen.

\section{Karakteristik Sosial Ekonomi}

Karakteristik sosial ekonomi petani dalam penerapan teknologi pola tanam padi jajar legowo 4:1 di Kelompoktani Gunung Harja dibagi dalam tiga kategori, untuk lebih jelasnya dapat dilihat pada Tabel 9 berikut ini.

Tabel 9. Karakteristik Sosial Ekonomi Petani Peserta Kegiatan Pola Tanam Padi Jajar Legowo 4 : 1

\begin{tabular}{|c|c|c|c|}
\hline No & Kategori & \multicolumn{2}{|c|}{ Jumlah } \\
\cline { 3 - 4 } & & $\begin{array}{c}\text { Responden } \\
\text { (Orang) }\end{array}$ & $\begin{array}{c}\text { Persentase } \\
(\mathbf{\%})\end{array}$ \\
\hline 1 & Rendah & 6 & 25 \\
\hline 2 & Sedang & 11 & 45,83 \\
\hline 3 & Tinggi & 7 & 29,17 \\
\hline \multicolumn{2}{|c|}{ Jumlah } & $\mathbf{2 4}$ & $\mathbf{1 0 0 , 0 0}$ \\
\hline
\end{tabular}

Dari Tabel 9 dapat diketahui bahwa karakteristik petani dalam penerapan teknologi pola tanam padi jajar legowo 4:1 sebagian besar berada pada kategori sedang sebanyak 11 orang atau 45,83 persen, kedua terbesar berada pada kategori tinggi sebanyak 7 orang atau 29,17 persen, dan yang terakhir berada pada kategori rendah sebanyak 6 orang orang atau 25 persen.

Persamaan regresi linier berganda sebagai berikut $Y=1,346+2,578 X_{1}+7,333 X_{2}+2,996 X_{3}+4,757$ $X_{4}+4,368 X_{5}+4,449 X_{6}$

\section{Umur Responden}

Umur responden secara parsial menunjukkan pengaruh positif terhadap penerapan teknologi pola tanam padi jajar legowo $4: 1$. Analisis statistik pada selang kepercayaan 95 persen, nilai $\alpha=0,05$ menunjukkan tingkat signifikan sebesar 0,000 yang masih berada di bawah 0,05 , dengan demikian maka keputusan statistiknya adalah $\mathrm{H0}$ ditolak dan $\mathrm{Ha}$ diterima (significant) artinya terdapat pengaruh positif umur responden terhadap penerapan teknologi pola tanam padi jajar legowo 4 : 1 .

Nilai koefisien elastisitas sebesar 2,578 menunjukkan bahwa tiap penambahan 1 (satu) persen faktor sosial ekonomi umur responden dengan asumsi faktor lain tetap (ceteris paribus) cenderung akan menaikkan penerapan teknologi pola tanam padi jajar legowo $4: 1$ sebesar 2, 578 persen.

\section{Tingkat Pendidikan Formal dan Non formal}

Hasil pengujian secara parsial tentang tingkat pendidikan formal dan non formal menunjukkan pengaruh positif (significant). Pada selang kepercayaan 95 persen, nilai $\alpha=0,05$ menunjukkan tingkat signifikan sebesar 0,000 yang masih berada di bawah 0,05, dengan demikian maka keputusan statistiknya adalah $\mathrm{H} 0$ ditolak dan $\mathrm{Ha}$ diterima (significant) artinya terdapat pengaruh positif antar tingkat pendidikan formal dan non formal terhadap penerapan teknologi pola tanam padi jajar legowo 4 : 1.

Nilai koefisien elastisitas sebesar 7,333 menunjukan bahwa setiap penambahan faktor sosial ekonomi tingkat pendidikan formal dan non formal sebesar 1 (satu) persen dengan asumsi faktor lain tetap (ceteris paribus) cenderung akan menaikkan penerapan teknologi pola tanam padi jajar legowo 4 : 1 sebesar 7,333 persen.

\section{Jumlah Tanggungan Keluarga}

Hasil pengujian secara parsial tentang jumlah tanggungan keluarga terhadap penerapan teknologi pola tanam padi jajar legowo $4: 1$ yang menunjukkan pengaruh positif (significant). Pada selang kepercayaan 95 persen, nilai $\alpha=0,05$ menunjukkan tingkat signifikan sebesar 0,000 yang masih berada dibawah 0,05, dengan demikian maka keputusan statistiknya adalah H0 ditolak dan Ha diterima (significant) artinya terdapat pengaruh positif antar jumlah tanggungan keluarga terhadap 
penerapan teknologi pola tanam padi jajar legowo $4: 1$.

Nilai koefisien elastisitas sebesar 2,996 menunjukkan bahwa setiap penambahan faktor sosial ekonomi jumlah tanggungan keluarga sebesar 1 (satu) persen dengan asumsi faktor lain tetap (ceteris paribus) cenderung akan menaikkan penerapan teknologi pola tanam padi jajar legowo 4 : 1 sebesar 2,996 persen.

\section{Luas Lahan}

Hasil pengujian secara parsial tentang luas lahan terhadap penerapan teknologi pola tanam padi jajar legowo 4 : 1 yang menunjukkan pengaruh positif (significant). Pada selang kepercayaan 95 persen, nilai $\alpha=0,05$ menunjukkan tingkat signifikan sebesar 0,000 yang masih berada di bawah 0,05, dengan demikian maka keputusan statistiknya adalah HO ditolak dan Ha diterima (significant) artinya terdapat pengaruh positif antar luas lahan terhadap penerapan teknologi pola tanam padi jajar legowo $4: 1$.

Nilai koefisien elastisitas sebesar 4,757 menunjukkan bahwa setiap penambahan faktor sosial ekonomi luas lahan sebesar 1 (satu) persen dengan asumsi faktor lain tetap (ceteris paribus) cenderung akan menaikkan penerapan teknologi pola tanam padi jajar legowo 4 : 1 sebesar 4,757 persen.

\section{Frekuensi Mengikuti Penyuluhan}

Hasil pengujian secara parsial tentang frekuensi mengikuti penyuluhan terhadap penerapan teknologi pola tanam padi jajar legowo 4 : 1 yang menunjukkan pengaruh positif (significant). Pada selang kepercayaan 95 persen, nilai $\alpha=0,05$ menunjukkan tingkat signifikan sebesar 0,000 yang masih berada di bawah 0,05, dengan demikian maka keputusan statistiknya adalah $\mathrm{H} 0$ ditolak dan $\mathrm{Ha}$ diterima (significant) artinya terdapat pengaruh positif antar frekuensi mengikuti penyuluhan terhadap penerapan teknologi pola tanam padi jajar legowo $4: 1$.

Nilai koefisien elastisitas sebesar 4,368 menunjukkan bahwa setiap penambahan faktor sosial ekonomi frekuensi mengikuti penyuluhan sebesar 1 (satu) persen dengan asumsi faktor lain tetap (ceteris paribus) cenderung akan menaikkan penerapan teknologi pola tanam padi jajar legowo $4: 1$ sebesar 4,368 persen.

\section{Pengalaman Bertani}

Hasil pengujian secara parsial tentang pengalaman bertani terhadap penerapan teknologi pola tanam padi jajar legowo 4 : 1 yang menunjukkan pengaruh positif (significant). Pada selang kepercayaan 95 persen, nilai $\alpha=0,05$ menunjukkan tingkat signifikan sebesar 0,000 yang masih berada di bawah 0,05, dengan demikian maka keputusan statistiknya adalah H0 ditolak dan Ha diterima (significant) artinya terdapat pengaruh positif antar pengalaman bertani terhadap penerapan teknologi pola tanam padi jajar legowo 4 : 1 .

Nilai koefisien elastisitas sebesar 4,449 menunjukkan bahwa setiap penambahan faktor sosial ekonomi pengalaman bertani sebesar 1 (satu) persen dengan asumsi faktor lain tetap ( ceteris paribus) cenderung akan menaikkan penerapan teknologi pola tanam padi jajar legowo 4 : 1 sebesar 4,449 persen.

\section{KESIMPULAN DAN SARAN \\ Kesimpulan}

Berdasarkan hasil penelitian dan pembahasan maka dapat diambil kesimpulan sebagai berikut:

1) Secara umum Tingkat Partisipasi individu pada Kelompoktani Gunung Harja sebagai besar termasuk dalam kategori dgress of citizen control (placation, citizen control, dan delegated power) sebanyak 16 orang atau 66,66 persen. Dan dgress of citizen control merupakan derajat yang paling tinggi di antara yang lain.b. tingkat partisipasi petani dalam Kelompoktani Gunung Harja termasuk dalam kategori tinggi dengan jumlah 13 orang responden atau 54,16 persen tingkat partisipasinya termasuk tinggi terhadap Kelompoktani Gunung Harja.

2) Tingkat karakteristik sosial ekonomi petaninya berada pada kategori sedang yaitu sebanyak 11 orang atau 45,83 persen, hal ini dikarenakan masih rendahnya tingkat pendidikan responden yaitu Tamat SD.3). Faktor sosial ekonomi petani yang meliputi, umur responden, tingkat pendidikanformal dan non formal, jumlah tanggungan keluarga, luas lahan, frekuensi mengikuti penyuluahn dan pengalaman bertani secara simultan dan parsial berpengaruh signifikan terhadap penerapan teknologi pola tanam padi jajar legowo $4: 1$.

\section{Saran}

Berdasarkan kesimpulan maka disarankan : 
1).Semua yang termasuk anggota pada Kelompoktani Gunung Harja di tingkatkan lagi partisipasinya, baik itu partisipasi dalam program-program pemerintah yang ditujukan untuk kelompok, dan partisipasi dalam program tanam padi jajar legowo $4: 1$ lebih ditingkatkan lagi, agar bisa terus berjalan. Karena disamping akan meningkatkan pendapatan anggota juga akan memperoleh manfaat yang lebih banyak serta akan sangat menunjang dalam kemajuan kelompok.

2).Berdasarkan pada kesimpulan, maka disarankan agar petani terus dibimbing, dibina dan dimonitoring dalam penerapan teknologi pola tanam padi jajar legowo $4: 1$ yang sudah diterapkan oleh petani, yang dapat meningkatkan produksi, hampir 25 Persen.

\section{DAFTAR PUSTAKA}

Firdaus. 2008. Swasembada Beras dari Masa ke. IPB Press. Bogor.

Ginting. 2011. Geografi : Jelajah Bumi dan Alam Semesta. Citra Praya. Bandung.

Hasyim, H. 2006. Analisis Hubungan Karakteristik Petani Kopi Terhadap Pendapatan (Studi Kasus : Desa Dolok Seribu Kecamatan Paguran Kabupaten Tapanuli Utara). Jurnal Komunikasi Penelitian Lembaga Penelitian. Universitas Sumatera Utara, Medan.

Misran. 2014. Studi Sistem Tanam Jajar Legowo Terhadap Peningkatan Produktivitas Padi Sawah. Jurnal Penelitian Pertanian Terapan Vol.14 (2).

Nazir,M. 2011. Metode Penelitian. Ghalia Indonesia. Bogor.

Soleh. 2013. Pembangunan Sektor Pertanian Melalui Pola Agribisnis Menuju Ketangguhan Perekonomian Indonesia. Journal On Social Economic Of Agriculture and Agribusiness Vol.2, No.9. hal. 674-685.

Sudjana. 2002. Teknik Analisis Regresi dan Korelasi bagi Para Peneliti. Tarsito. Bandung. 
